\title{
Ethnic Disparities in Access to Emergency Medical Services and in Quality of Care in Children Diagnosed and Treated for Asthma Exacerbation in The Pediatric Emergency Department
}

\author{
Guy Hazan, Fruchtman Y, Raouf Nassar, Yaacov Bistritzer, Amir Horev and Eugene Leibovitz* \\ Department of Pediatrics, Faculty of Health Sciences, Soroka University Medical Center, Ben-Gurion University of the Negev, Israel
}

Submission: July 16, 2019; Published: September 03, 2019

*Corresponding author: Prof. Eugene Leibovitz, MD, Department of Pediatrics, Faculty of Health Sciences, Soroka University Medical Center, BenGurion University of the Negev, P.0. Box 151, Beer-Sheva 84101, Israel

\begin{abstract}
Objectives: Significant disparities exist in asthma management based on race, socioeconomic status and inappropriate access to medical care. We examined the ethnic disparities in access and in quality of care in southern Israel among Bedouin and Jewish children treated for asthma exacerbation (AE) in the Pediatric Emergency Department (PED).

Methods: In this retrospective study conducted during 2011-2013, a structured questionnaire assessed ethnic gaps in parental reports of doctor-diagnosed asthma and hospital PED management.

Results: 1132 children aged <18 years (61.7\% Bedouins, 38.3\% Jews) who visited the PED with an AE were enrolled. The highest number of patients was recorded in the 1-2 years age group (324, 28.6\%, with 197, 28.2\%, Bedouin patients and 127, 29.3\%, Jewish patients). More Jewish children received at home their initial treatment compared with Bedouin children $(57.7 \%$ vs. $49.1 \%, \mathrm{P}<0.001)$. More Jewish patients were discharged compared with Bedouin patients $(188,43.4 \%$ vs. $186,26.6 \%, \mathrm{P}<0.001)$. No differences were recorded between Bedouin and Jewish children in accessibility to medical services, transportation to medical facilities and delivery of care. Bedouin households had higher incidence of smokers, lower income and less educated and more unemployed parents than Jewish households. More Bedouins did not receive prophylaxis, were previously treated for asthma, did not receive immediate home treatment for the $\mathrm{AE}$, received steroids and short-acting beta-agonists in the community, had lower oxygen saturation levels at PED and required hospitalization. No differences were recorded between Bedouin and Jewish patients in use of inhaled beta-agonists and steroids administered at PED and during hospitalization and prescribed at discharge.
\end{abstract}

Conclusions: Although no differences were recorded in access and delivery of care, suboptimal asthma prophylaxis and disease control were associated with ethnic and socioeconomic disparities. Non-adherence to asthma standard of care guidelines and lack of personalized action programs in community and PED emerged as major management concerns in both ethnic populations.

Keywords: Asthma; Children; Community; Prophylaxis; Guidelines

\section{Introduction}

Racial and ethnic disparities in health care have persisted and even increased despite overall improvement in minority health $[1,2]$. The possible roles of behavioral, cultural, social, economic, biological, and environmental factors have been extensively analyzed in the adult populations, but the information on racial and ethnics disparities in children care is limited. In a report on disparities by the Agency for Healthcare Research and Quality, there were $>3$ times as many disparity measures for adults than for children and only $15 \%$ of measures were child specific $[3,4]$.

Among diseases requiring frequent visits to community physicians, pulmonary diseases specialists and pediatric emergency departments (PED) and leading also to high rates of hospitalizations, asthma is a leading chronic illness among children in the United States [5,6]. Asthma affects individuals of all ages, races, ethnicities and incomes, but the rates of black and poor children suffering from this condition are disproportionately 
high [7]. Asthma prevalence among young children, and particularly among low-income children of non-white population, has continued to increase in the past 2 decades, despite major progress in research and management and increased scientific understanding of its causes and treatments $[8,9]$. Among multiple factors contributing to asthma occurrence and its severity, environmental factors, low birth weight, socioeconomic and demographic differences, parents' history of asthma, access to and use of medical care and health insurance and also parents' health and health-related behaviors have been identified and thoroughly analyzed [10].

The increased prevalence of asthma has been accompanied by a significant increase in the number of ED visits and hospitalizations due to asthma $[10,11]$. In the United States, the ED visits or hospitalizations rates in African Americans were found 3 times higher than those reported for non-Hispanic whites [10]. The age-adjusted mortality rates due to asthma were more than 3 times greater for urban African Americans than for whites [12].

In a report of the Israel National Institute for Health Policy Research [13], the rates of asthma were found twice higher among low-income Israeli population compared to higher income segments of the population. These differences were considered related to physical living conditions and specific way-of-life characteristics and behaviors. The rates of patients receiving prophylactic treatment for asthma were around 10\% lower among the low-income patients.

In the Negev region of southern Israel two populations of children live side by side: Jewish children, largely urban with lifestyle comparable to a Western population and Bedouin children (a population formerly composed of desert nomads and now in transition to a Western lifestyle). The disease patterns and rates differ between these two populations, but both have access to the same medical services (both clinics and hospitalization services) [14-16]. Studies on factors explaining the socioeconomic disparities in health within ethnic minorities in Israel are scarce $[17,18]$.

This study aimed to determine the possible ethnic disparities in access to emergency medical services and in quality of care among Bedouin and Jewish children $>1$ year of age with AE treated at the PED of the Soroka University Medical Center in southern Israel, with the use of a 2-year (2012-2013) representative patient sample. The study aimed to determine if ethnic differences exist in some or all asthma management characteristics among these two pediatric populations and will try to explain the patterns of visits with $\mathrm{AE}$ among children in Southern Israel using the disparities identified.

\section{Patients and Methods}

\section{Study population and settings}

Soroka University Medical Center is the only general hospital in the Negev region of southern Israel and provides primary and tertiary health services to the entire population $(>700,000$ inhabitants, of them around 250,000 children) of the region [15]. The PED of the hospital provides care to $>35,000$ children aged 0-18 years/year, of them $>1000$ cases are diagnosed as AE.

Medical insurance in Israel for children is universal and is provided free of charge. There are no financial or other barriers for health-care service use in the region. Overall treatment policies are identical in the 2 populations since drug formulations, prices, and availability of drugs is the same at all General Health Insurance Plan clinics. Criteria for referral to a hospital are also similar [16-18].

\section{Study conduct}

Data collection was conducted during 1st January 2012 to 31st December 2013. The research protocol was approved by the Ethics Committee of the Soroka University Medical Center. A standardized, structured bilingual (Hebrew and Arabic) questionnaire was completed by the patients' parents at the time of sampling (visit at PED) and/or by phone during a 2 weeksperiod after the PED visit (Appendix 1). The questionnaire asked specifically on sociodemographic data, asthma history, pre-exacerbation history, access and availability of emergency medical services, severity of asthma, PED disposition, length of hospitalization and recommended prophylaxis at discharge (see detailed questionnaire in Appendix 1).

\section{Data analysis}

Results were analyzed using the Statistical Package for the Social Sciences for Windows (SPSS version 15.0 and above) software package. Differences between the 2 populations were evaluated using the student t-test for continuous variables such as time from onset of symptoms to arrival to PED and using oneway ANOVA when comparing more than 2 populations. Univariate analysis, i.e. Chi-square (c2) was used to test statistical significance of differences for dichotomous variables. A two-sided $\mathrm{P}$ value of $<0.05$ was considered significant and appropriate odds ratios were calculated with 95\% Confidence Intervals.

\section{Results}

Overall, 1231 children aged $<18$ years who visited the PED with an $\mathrm{AE}$ episodes were identified. Completed interviews providing information on the management of the AE event were obtained in 1132 children (the study population). The remaining 99 were ineligible, being unreachable because of disconnected, nonworking or wrong telephone numbers. None of the parents approached at the PED refused to complete the questionnaires.

Of study patients, 699 (61.7\%) were of Bedouin ethnicity and 433 (38. 3\%) were of Jewish ethnicity. There were 734 (64.8\%) males and 398 (35. 2\%) females. Mean age was 55.55 months, with no difference between the Bedouin and Jewish children $(\mathrm{P}=0.26)$. The highest number of patients was recorded in the 1-2 years age group (324, 28.6\%, with 197, 28.2\%, Bedouin patients and $127,29.3 \%$, Jewish patients). Overall, there were $772(68.2 \%)$ 
in the age group $1-4$ years $(479,68.5 \%$ and $293,67.7 \%$ Bedouin and Jewish patients, respectively).

No background medical conditions were reported in 945 $(83.5 \%)$ patients. The number of children with background medical conditions was higher in Bedouins compared with Jewish patients $(170 / 699,24.3 \%$ vs. 58/433, 13.4\%, $\mathrm{P}<0.001)$. Hematological (30 children), neurological (27), cardiovascular (23), allergic-immunologic and respiratory conditions (22 in each group) were the most commonly diagnosed conditions.
More Bedouin parents had no high school and beyond education (Table 1). The unemployment rates were higher among Bedouin fathers compared with the Jewish ones $(13.3 \%$ vs. $6.9 \%, \mathrm{P}<0.001)$; $84.6 \%$ of the Bedouin mothers were not working. The household income was higher in Jewish families; a household income $<5000$ Israeli shekels (around 1500 American dollars) was reported in 46.5\% Bedouin families vs. $8.2 \%$ Jewish families. More Bedouin fathers were smokers compared with Jewish fathers; more Jewish mothers smoked compared with Bedouin mothers. Both parents were smoking more frequently in the Jewish families compared with the Bedouin families $(\mathrm{P}<0.001)$.

Table 1: Parental education, working status, family income and smoking habits.

\begin{tabular}{|c|c|c|c|c|}
\hline & Bedouins & Jews & P value & Total \\
\hline Father education & $N=693$ & $\mathrm{~N}=408$ & & $N=1101$ \\
\hline$<8$ school years & $294(42.4)$ & $10(2.5)$ & $<0.001$ & $304(27.6)$ \\
\hline 12 years (high school) & $353(50.9)$ & $295(72.3)$ & $<0.001$ & $648(58.9)$ \\
\hline Some college & $15(2.2)$ & $28(6.9)$ & $<0.001$ & $43(3.9)$ \\
\hline College graduate & $26(3.8)$ & $65(15.9)$ & $<0.001$ & $91(8.3)$ \\
\hline Postgraduate & $5(0.7)$ & $10(2.4)$ & 0.02 & $15(1.4)$ \\
\hline 12 years or more & $399(57.6)$ & $398(97.5)$ & $<0.001$ & $797(72.4)$ \\
\hline Mother education & $\mathrm{N}=695$ & $\mathrm{~N}=\mathbf{4 1 9}$ & & $\mathrm{N}=1114$ \\
\hline$<8$ school years & $405(58.3)$ & $6(1.4)$ & $<0.001$ & $411(36.9)$ \\
\hline 12 years (High school) & $229(32.9)$ & $299(71.4)$ & $<0.001$ & $528(47.4)$ \\
\hline Some college & $19(2.7)$ & $22(5.3)$ & 0.04 & $41(3.7)$ \\
\hline College graduate & $40(5.8)$ & $73(17.4)$ & $<0.001$ & $113(10.1)$ \\
\hline Postgraduate & $2(0.2)$ & $19(4.6)$ & $<0.001$ & $21(1.8)$ \\
\hline 12 years or more & $290(41.7)$ & $413(98.6)$ & $<0.001$ & $703(63.1)$ \\
\hline Father working status & $N=693$ & $N=406$ & & $N=1099$ \\
\hline Not working & $92(13.3)$ & $28(6.9)$ & 0.001 & $120(10.9)$ \\
\hline Working & $601(86.7)$ & $378(93.1)$ & & $979(89.1)$ \\
\hline Mother working status & $N=694$ & $N=413$ & & $\mathrm{~N}=1107$ \\
\hline Not working & $587(84.6)$ & $56(13.6)$ & $<0.001$ & $643(58.1)$ \\
\hline Working & $107(15.4)$ & $357(86.4)$ & & $464(41.9)$ \\
\hline Family income (IS)* & $\mathrm{N}=649$ & $\mathrm{~N}=\mathbf{3 8 0}$ & & $N=1029$ \\
\hline $0-5000$ & $302(46.5)$ & $31(8.2)$ & $<0.001$ & $333(32.4)$ \\
\hline $5000-10,000$ & $326(50.2)$ & $258(67.9)$ & $<0.001$ & $584(56.8)$ \\
\hline $10,000-15,000$ & $21(3.2)$ & $91(23.9)$ & $<0.001$ & $112(10.9)$ \\
\hline Father smoking & $N=689$ & $N=423$ & & $\mathrm{~N}=1112$ \\
\hline Smoker & $464(67.3)$ & $169(40.0)$ & $<0.001$ & $633(56.9)$ \\
\hline Nonsmokers & $225(32.7)$ & $254(60.0)$ & & $479(43.1)$ \\
\hline Mother smoking & $N=689$ & $\mathrm{~N}=423$ & & $\mathrm{~N}=1112$ \\
\hline Smokers & $25(3.6)$ & $82(19.4)$ & $<0.001$ & $107(9.6)$ \\
\hline Nonsmokers & $664(96.4)$ & $341(80.6)$ & & $1005(90.4)$ \\
\hline Father and mother & $N=689$ & $\mathrm{~N}=423$ & & $\mathrm{~N}=1112$ \\
\hline Smokers & $474(68.8)$ & $191(45.2)$ & $<0.001$ & $665(59.8)$ \\
\hline Nonsmokers & $215(31.2)$ & $232(54.8)$ & & $447(40.2)$ \\
\hline
\end{tabular}


Overall, $52.4 \%$ of the patients received at home the first treatment for the present AE attack. More Jewish children received at home their initial treatment compared with Bedouin children (57.7\% vs. $49.1 \%, \mathrm{P}<0.001)$. More Bedouin children approached an HMO community clinic for the initial treatment $36.8 \%$ vs. $25.3 \%, \mathrm{P}=0.005$ ). More Bedouin children were initially treated by private physicians compared with Jewish children $(5.9 \%$ vs. $2.9 \%$, $\mathrm{P}=0.01$ ); $9.5 \%$ of the patients did not receive any anti-asthmatic treatment before their PED visit.

The mean period from first asthma symptoms till the first medical service received were $28.4 \pm 38.5$ hours, with no differences between Jewish and Bedouin patients or between patients living in towns or in rural settlements. The number of patients with a referral letter from their community physician was higher among Bedouin children compared with Jewish children (90.4\% vs. $79.7 \%, \mathrm{P}<0.01)$. The patients were referred to PED by pediatricians $(82.8 \%)$, general practitioners (5.9\%) and family medicine specialists (5.2\%).

Mean time of arrival to PED was $48.62 \pm 56.12$ hours and was longer in patients living in towns compared with patients living in rural areas. No differences were found in the time of arrival at the PED between the Bedouin and Jewish children, with no relation between their living areas.

Overall, 374/1132 (33\%) patients were discharged. More Jewish patients were discharged compared with Bedouin patients $(188,43.4 \%$ vs. $186,26.6 \%, \mathrm{P}<0.001)$. The duration of hospitalization was longer in Bedouin children compared with
Jewish children ( $1.94 \pm 3.82$ days vs. $1.51 \pm 1.1$ days, $\mathrm{P}=0.09$ ). Six patients were admitted to PICU (5 Bedouin and 1 Jewish patient).

The mean age at the first asthma episode was 20.2 months, with no differences between the Bedouin and Jewish children (Table 2). No differences were recorded between the number of Bedouin and Jewish children who developed the first asthma episode in the various age groups analyzed. Three hundred and three $(26.8 \%)$ patients were hospitalized for an AE during the previous year, with no differences between Bedouin and Jewish children. Four hundred and nine (36.1\%) visited at least once at the PED during the previous year. Overall, 1056 (95.7\%) patients visited HMO community clinics during the last year, with a significantly higher number of visits reported in Bedouin children compared with Jewish children (676, 98\% vs. $380,92 \%, \mathrm{P}<0.001)$; $247(22 \%)$ patients visited a pulmonary disease specialist during the previous year with no differences between Bedouin and Jewish children. One single visit to a pulmonary disease specialist was reported more frequently in Jewish patients (19.1\% vs. $12.6 \%$ $\mathrm{P}=0.004)$ and 3 visits were reported more in Bedouin children (1.9\% vs. $0.2 \%, \mathrm{P}=0.03$ ). Most of the study patients (909, 80.3\%) received treatment with $\beta$-agonists during the previous 3 months, with no differences between Bedouin and Jewish children; 779 $(68.8 \%)$ received inhaled steroids with a trend for a more frequent use among the Jewish patients $(311,71.8 \%$ vs. $468,67 \%, \mathrm{P}=0.09)$; $825(76.2 \%)$ were treated with short oral steroid courses during the previous year, more frequently in Bedouin children compared with Jewish children $(533,79.4 \%$ vs. $292,71 \%, P=0.002)$.

Table 2: Disease history and treatment of enrolled patients ( $\mathrm{N}=$ no. of patients evaluated).

\begin{tabular}{|c|c|c|c|c|}
\hline & Bedouins & Jews & P value & Total \\
\hline Age at first episode & $N=618$ & $\mathrm{~N}=377$ & & $\mathrm{~N}=995$ \\
\hline Mean (months) & 19.8 & 20.92 & 0.45 & 20.2 \\
\hline$<1 \mathrm{yr}$ & $229(37.1)$ & $135(35.8)$ & 0.5 & $364(36.6)$ \\
\hline $1-2 \mathrm{yr}$ & $166(26.8)$ & $102(27.1)$ & 0.94 & $268(26.9)$ \\
\hline $2-4 \mathrm{yr}$ & $102(16.5)$ & $68(17.9)$ & 0.64 & $170(17.0)$ \\
\hline$>4 \mathrm{yr}$ & $121(19.6)$ & $72(19.1)$ & 0.74 & $193(19.4)$ \\
\hline \multirow[t]{2}{*}{ Hospitalization for asthma during last year } & $N=696$ & $\mathrm{~N}=433$ & & $\mathrm{~N}=1129$ \\
\hline & $198(28.4)$ & $105(24.2 \%)$ & 0.12 & $303(26.8 \%)$ \\
\hline ED visits with asthma during last year & $N=699$ & $N=433$ & & $\mathrm{~N}=1132$ \\
\hline$\geq 1$ visit & $266(38.1)$ & $143(33.0)$ & 0.09 & 409 (36.1) \\
\hline 1 visit & $147(20.1)$ & $82(18.9)$ & 0.39 & $229(20.2)$ \\
\hline 2 visits & $64(9.2)$ & $23(5.3)$ & 0.02 & $87(7.7)$ \\
\hline 3 visits & $25(3.6)$ & $18(4.2)$ & 0.62 & $43(3.8)$ \\
\hline$>3$ visits & $30(4.3)$ & $20(4.6)$ & 0.8 & $50(4.4)$ \\
\hline Visits at HMO community clinics during last year & $N=690$ & $N=413$ & & $\mathrm{~N}=1103$ \\
\hline$\geq 1$ visit & $676(98.0)$ & $380(92.0)$ & $<0.001$ & 1056 (95.7) \\
\hline 1 visit & $140(20.3)$ & $60(14.5)$ & 0.07 & $200(18.1)$ \\
\hline 2 visits & $150(21.7)$ & $95(23.0)$ & 0.12 & $245(22.2)$ \\
\hline
\end{tabular}




\section{Academic Journal of Pediatrics \& Neonatology}

\begin{tabular}{|c|c|c|c|c|}
\hline 3 visits & $160(23.2)$ & $94(22.8)$ & 0.87 & $254(23.0)$ \\
\hline$>3$ visits & $226(32.8)$ & $131(31.7)$ & 0.72 & $357(32.4)$ \\
\hline Visits at pulmonary disease specialist during last year & $N=696$ & $\mathrm{~N}=429$ & & $\mathrm{~N}=1125$ \\
\hline$\geq 1$ visit & $145(20.8)$ & $102(23.8)$ & 0.25 & $247(22.0)$ \\
\hline 1 visit & $88(12.6)$ & $82(19.1)$ & 0.004 & $170(15.1)$ \\
\hline 2 visits & $31(4.5)$ & $12(2.8)$ & 0.21 & $43(3.8)$ \\
\hline 3 visits & $13(1.9)$ & $1(0.2)$ & 0.03 & $14(1.2)$ \\
\hline$>3$ visits & $13(1.9)$ & $7(1.6)$ & 0.77 & $20(1.8)$ \\
\hline \multirow[t]{2}{*}{ Beta-agonists during last 3 months } & $N=699$ & $\mathrm{~N}=433$ & & $\mathrm{~N}=1132$ \\
\hline & $571(81.7)$ & $338(78.1 \%)$ & 0.14 & $909(80.3)$ \\
\hline \multirow[t]{2}{*}{ Inhaled steroids (Budicort) during last year } & $N=699$ & $N=433$ & & $\mathrm{~N}=1132$ \\
\hline & $468(67.0)$ & $311(71.8)$ & 0.09 & $779(68.8)$ \\
\hline Short PO steroid course during last year: & $N=671$ & $\mathrm{~N}=\mathbf{4 1 1}$ & & $\mathrm{N}=1082$ \\
\hline$\geq 1$ visit & $533(79.4)$ & $292(71.0)$ & 0.002 & $825(76.2)$ \\
\hline 1 course & $114(17.0)$ & $76(18.5)$ & 0.53 & $190(17.6)$ \\
\hline 2 courses & $238(35.5)$ & $133(32.4)$ & 0.3 & $371(34.3)$ \\
\hline 3 courses & $105(15.6)$ & $49(11.9)$ & 0.09 & $154(14.2)$ \\
\hline 4 courses & $25(3.7)$ & $5(1.2)$ & 0.02 & $30(2.8)$ \\
\hline Over 5 courses & $51(7.4)$ & $29(6.9)$ & 0.57 & $80(7.5)$ \\
\hline Mean \pm SD & $2.17 \pm 2.7$ & $1.90 \pm 2.61$ & 0.05 & $2.08 \pm 2.77$ \\
\hline \multirow[t]{2}{*}{ Spacer availability at home } & $N=699$ & $\mathrm{~N}=433$ & & $\mathrm{~N}=1132$ \\
\hline & $362(51.8)$ & $288(66.5)$ & $<0.001$ & $650(57.4)$ \\
\hline \multirow[t]{2}{*}{ Nebulizer availability at home } & $N=699$ & $\mathrm{~N}=433$ & & $\mathrm{~N}=1132$ \\
\hline & $466(66.7)$ & $361(83.4)$ & $<0.001$ & $827(73.1)$ \\
\hline
\end{tabular}

Table 3 describes the patient's asthma history during the last 100 days prior to the present $\mathrm{AE}$ attack. The mean $( \pm \mathrm{SD})$ number of days without symptoms during the last 100 days was $91.1 \pm 13.8$, with no difference between Bedouin and Jewish children. Only 5 of the enrolled children reported $<10$ days without symptoms during this period. The mean $( \pm \mathrm{SD})$ number of visits to community HMO clinics due to asthma symptoms was $1.73 \pm 1.74$ visits, with no difference between the 2 ethnic populations. The Jewish children has more days with moderate or severe disease, used more Montelukast prophylaxis, more inhaled steroids and received more combination therapy (Montelukast + inhaled steroids) compared with Bedouin children.

Table 3: Asthma history (symptoms) during last 100 days before presenting with asthma exacerbation.

\begin{tabular}{|c|c|c|c|c|}
\hline & Bedouins & Jews & P value & Total \\
\hline & $\mathbf{N}=\mathbf{6 9 2}$ & $\mathbf{N = 4 2 6}$ & $\mathbf{N 1 1 8}$ \\
\hline Days w/o symptoms & $91.0 \pm 14.4$ & $91.2 \pm 12.9$ & 0.82 & $91.1 \pm 13.8$ \\
\hline $0-10$ & $3(0.4)$ & $2(0.5)$ & 1.0 & $5(0.4)$ \\
\hline $11-30$ & $16(2.3)$ & $5(1.2)$ & 0.17 & $21(1.9)$ \\
\hline $31-60$ & $15(2.2)$ & $10(2.3)$ & 0.84 & $25(2.2)$ \\
\hline $61-100$ & $658(95.1)$ & $409(96.0)$ & 0.47 & $1067(95.4)$ \\
\hline Median & $\mathbf{N = 6 9 2}$ & $\mathbf{N = 4 2 3}$ & $\mathbf{N = 1 1 1 5}$ \\
\hline No. visits to community HMO with asthma symptoms & $1.74 \pm 1.73$ & $1.73 \pm 1.75$ & 0.93 & $\mathrm{~N}=1115$ \\
\hline Mo. days with moderate /severe disease & 1.0 & 1.0 & 1.0 \\
\hline Median & $\mathbf{N = 6 9 0}$ & $\mathbf{N}=\mathbf{4 2 6}$ & $\mathbf{N = 1 1 1 6}$ \\
\hline & $2.04 \pm 3.66$ & $3.08 \pm 4.90$ & $<0.001$ & $2.43 \pm 4.20$ \\
\hline & 1.0 & 1.0 & 1.0 \\
\hline
\end{tabular}




\section{Academic Journal of Pediatrics \& Neonatology}

\begin{tabular}{|c|c|c|c|c|}
\hline & $60(8.6)$ & $66(15.2)$ & $<0.001$ & $126(11.1)$ \\
\hline \multirow[t]{2}{*}{ Inhaled steroids (Budicort) only } & $\mathrm{N}=699$ & $N=433$ & & $\mathrm{~N}=1132$ \\
\hline & $106(15.2)$ & $99(22.9)$ & $<0.001$ & $205(18.1)$ \\
\hline \multirow[t]{2}{*}{ Monteleukast + Inhaled steroids } & $N=699$ & $N=433$ & & $\mathrm{~N}=1132$ \\
\hline & $17(2.4)$ & $21(4.8)$ & 0.03 & $38(3.4)$ \\
\hline \multirow[t]{2}{*}{ Inhaled steroids + long acting beta-agonists (Symbicort) } & $N=699$ & $\mathrm{~N}=433$ & & $\mathrm{~N}=1132$ \\
\hline & $20(2.9)$ & $2(0.5)$ & 0.004 & $22(1.9)$ \\
\hline \multirow[t]{2}{*}{ Use of beta-agonists only for $\geq 3$ weeks* continuously or intermittently } & $\mathrm{N}=699$ & $\mathrm{~N}=433$ & & $\mathrm{~N}=1132$ \\
\hline & $9(1.3)$ & $16(3.7)$ & 0.007 & $25(2.2)$ \\
\hline
\end{tabular}

$\mathrm{N}=$ no. of patients evaluated

*IS=Israeli shekels

Seven hundred and seventeen (63.3\%) received the initial antiasthmatic therapy at home, more common in Jewish children than in Bedouin children (297, 68.6\% vs. 420,60.1\%, P=0.004) (Table 4). More Jewish patients received home therapy with short acting $\beta$-agonists compared with Bedouin children (287, 66.3\% vs. $413,59.1 \%, \mathrm{P}=0.015) ; 567$ (50.1\%) received treatment at the HMO community clinics (more Bedouin patients compared with Jewish patients: $55.5 \%$ vs. $41.3 \%, \mathrm{P}<0.001$ ). More Bedouin patients received steroids (oral or injectable, $28.5 \%$ vs. $19.6 \%$, $\mathrm{P}=0.001)$ and short acting $\beta$-agonists $(47.9 \%$ vs.35.1\%, $\mathrm{P}<0.001)$ compared with Jewish patients.

Table 4: Asthma history (symptoms) during last 100 days before presenting with asthma exacerbation.

\begin{tabular}{|c|c|c|c|c|c|c|c|c|}
\hline & \multicolumn{2}{|c|}{ Home treatment } & \multirow[b]{2}{*}{$P$ value } & \multirow[b]{2}{*}{$\begin{array}{c}\text { Total } \\
\mathrm{N}=1132\end{array}$} & \multicolumn{4}{|c|}{ HMO community clinic treatment } \\
\hline & $\begin{array}{c}\text { Bedouins } \\
\mathrm{N}=699\end{array}$ & Jews $\quad N=433$ & & & $\begin{array}{c}\text { Bedouins } \\
\mathrm{N}=699\end{array}$ & $\begin{array}{c}\text { Jews } \\
\mathrm{N}=433\end{array}$ & $P$ value & $\begin{array}{c}\text { Total } \\
\mathrm{N}=1132\end{array}$ \\
\hline Received treatment & $420(60.1)$ & $297(68.6)$ & 0.004 & $717(63.3)$ & $388(55.5)$ & $\begin{array}{c}179 \\
(41.3)\end{array}$ & $<0.001$ & $567(50.1)$ \\
\hline Steroids (PO or injectable) & $83(11.9)$ & $66(15.2)$ & 0.103 & $149(13.2)$ & $199(28.5)$ & $\begin{array}{c}85 \\
(19.6) \\
\end{array}$ & 0.001 & $282(25.1)$ \\
\hline Short acting beta-agonists (Bricalin, Ventolin) & $413(59.1)$ & $287(66.3)$ & 0.015 & $700(61.8)$ & $335(47.9)$ & $\begin{array}{c}152 \\
(35.1)\end{array}$ & $<0.001$ & $487(43.0)$ \\
\hline High-dose inhaled steroids & $0(0.0)$ & $3(0.7)$ & 0.056 & $3(0.3)$ & $2(0.3)$ & $2(0.5)$ & 0.64 & $4(0.4)$ \\
\hline Use of aerochamber & $8(1.1)$ & $17(3.9)$ & 0.002 & $25(2.2)$ & $5(0.7)$ & $6(1.4)$ & 0.35 & $11(1.0)$ \\
\hline Use of inhaler (electric device) & $23(3.3)$ & $22(5.1)$ & 0.134 & $45(4.0)$ & $8(1.1)$ & $1(0.2)$ & 0.16 & $9(0.8)$ \\
\hline Oxygen & $0(0.0)$ & $0(0.0)$ & - & - & $73(10.4)$ & $\begin{array}{c}35 \\
(8.1)\end{array}$ & 0.19 & $108(9.5)$ \\
\hline
\end{tabular}

One hundred and seventy-six (15.5\%) patients were transported to ED by ambulance, with no difference between Bedouin and Jewish children (14.6\% vs. $17.1 \%, \mathrm{P}=0.26)$. Oxygen was administered during transport to $97.1 \%$ of the patients, with no difference between Bedouin and Jewish children $(98.0 \%$ vs. $95.8 \%, \mathrm{P}=0.65)$.

The oxygen saturation was examined at PED in 1131 (99.9\%); the mean $( \pm \mathrm{SD})$ oxygen saturation measured was higher in Jewish patients compared with Bedouin ones (92.92 \pm 3.55 vs. 91.83 \pm $4.38, \mathrm{P}<0.001)$. No differences were recorded in the percentages of short acting $\beta$-agonists (537, 76.8\% in Bedouins vs. 343, 79.2\% in Jewish children, $\mathrm{P}=0.35$ ) and inhaled or oral steroids $(412$, $59.4 \%$ in Bedouins vs. $260,60.6 \%$ in Jewish children, $\mathrm{P}=0.68$ ) used. Chest X-rays were performed in 580 patients $(371,53.1 \%$ Bedouins vs. 209, 48.3\% Jewish patients, $\mathrm{P}=0.12$ ).
Preventive therapy was recommended in $681(60.2 \%)$ patients), with no differences between Bedouin (58.4\%) and Jewish (53.0\%) children. Inhaled and oral steroids were prescribed in $789(69.7 \%)$ and $1130(99.8 \%)$ of the patients, with no differences between Bedouin and Jewish children. Montelukast and long-acting $\beta$-agonists were prescribed in 93(8.2\%) and $24(2,1 \%)$ patients, with no differences between Bedouin and Jewish children.

\section{Discussion}

Despite changes in medical technology and major progress in health care, minorities have continued to suffer from excess mortality for several common health conditions despite improvements in the socioeconomic status [19-21]. Lack of access to adequate medical care may lead to greater disease severity upon presentation to the ED, and therefore may account to some extent for higher rates of mortality and morbidity [22]. 
The objectives of this study were to determine the existing disparities in asthma management in children at the levels of the community initial treatment and the PED, to reveal general causes accounting for such disparities and to propose strategies for change and areas where future research is needed. We showed in the present study that:

I. More than $60 \%$ of the patients treated for acute exacerbation of asthma were of Bedouin ethnicity and the majority of the children were $<1-4$ years of age;

II. The Bedouin households had more smokers and a lower income, and the parents were less educated and more unemployed compared with Jewish households;

III. No differences were recorded between Bedouin and Jewish children in access to care in respect to accessibility of medical services in the community and at PED and in transportation to these facilities;

IV. More Bedouin children did not receive anti-asthmatic prophylaxis, had more previous visits to community clinics during the last year, did not receive immediate home treatment, were initially treated by private physicians and received the first anti-asthmatic treatment only in the community clinics;

V. More Bedouin children received steroids and shortacting beta-agonists in the community compared with the Jewish children;

VI. More Bedouin children had lower oxygen saturation levels at PED and were hospitalized compared with the Jewish children;

VII. No differences were recorded between Bedouin and Jewish patients in the treatments with inhaled beta-agonists and oral steroids at PED;

VIII. Short-term therapy with inhaled and oral steroids and anti-asthmatic prophylaxis were recommended at discharge in around $60 \%$ patients, with no differences between Bedouin and Jewish children.

No differences were recorded in our study between the 2 ethnic populations studied regarding the access to care to medical services in the community and at PED, in transportation to these facilities and in accessibility to various investigations and to anti-asthmatic treatment provided at all levels. We should explain that in Israel a national health insurance law exists and all citizens, including Bedouin Moslem citizens, are well insured. The accessibility to primary and consulting health care services is very high and could not confound our results.

We found that non-adherence to asthma standard of care guidelines and lack of personalized action programs in community and pulmonary disease specialists' clinics, ED and at discharge emerged as major management concerns in both ethnic populations. Specifically, the overall percentages of patients receiving prophylaxis during the period preceding the AE were low.
Additionally, the overall referral rates to pulmonary specialists were low, both before and after the PED visit. Although the topic of providing an individualized disease management program (at the community level, at discharge from ED or from hospitalization or by a pulmonary specialist) was not dealt in the questionnaire used, the details revealed by the questionnaire used in our study showed a considerable lack of uniformity in the management of $\mathrm{AE}$ episodes and in the follow-up recommendations received by the patients.

Guidelines for asthma management from several national asthma education and prevention programs are available [23-25] but have not been yet appropriately integrated into primary care [26]. Undertreatment of asthma, as demonstrated by low rates of inhaled corticosteroids use, has been consistently observed in children and adults in urban and nonurban settings. In a study examining differences in the effectiveness of an interventional management program in 2,362 children (including an initial parental survey related to diagnosis, a clinician evaluation form on disease severity and a management plan according to disease severity), the initial hospitalization rates were high and subsequently decreased by $53 \%$ for black children and $33 \%$ for Hispanic children after the intervention [27]. The PED visits decreased for Hispanic patients, the outpatient visits decreased for both black and Hispanic children and the inhaled corticosteroids prescription rates increased significantly for both populations after the initiation of the program.

The available clinical guidelines for asthma management do not include separate standards for children, but there is consensus that most steps involved in asthma care are similar across the age spectrum. Many guidelines recommendations (like need for assessment of asthma control status, evaluation of asthma symptoms severity, administration of oral/intravenous steroids within 1 hours of presentation, need for a structured discharge plan in hospitalized patients and need for follow-up examination following discharge) are directly relevant to the management of children with AE. However, it is understandable that some of these recommendations may not be practical and achievable targets for all asthma patients. Scribano et al. [28] attempted to measure provider adherence to PED clinical practice guidelines and to determine factors associated with provider nonadherence, in a prospective cohort study of 369 children with AE seen in PED during 1998-1999 and requiring hospitalization. Sixty-eight percent of the patients were managed with complete adherence to the guidelines. Of the $32 \%$ with some form of nonadherence, most $(63 \%)$ were children $>6$ years.

In the present study, short-acting beta-agonists were recommended at discharge (from PED or from hospitalization) in more than $99 \%$ of the patients and preventive therapy was recommended in $60.2 \%$ patients, with no differences between Bedouin and Jewish children. Inhaled and oral steroids were prescribed at discharge in $69.7 \%$ and $99.8 \%$ of the patients, with no differences between Bedouin and Jewish children. 
Smith et al. [29] conducted telephone interviews with parents of children with persistent asthma, described the rates of suboptimal control and controller medication underuse and tried to identify potentially modifiable parental behaviors and beliefs associated with these outcomes. Thirty-seven percent of the children were found to have suboptimal asthma control, more commonly in Hispanic children (51\%) than in black (37\%) or white $(32 \%)$ children. In multivariate analyses, suboptimal control was associated with potentially modifiable factors including low parental expectations for symptom control and high levels of worry about competing household priorities [29]. Peled et al. [30] analyzed the database from the largest HMO in southern Israel and a list of six markers ( $(>55$ days of relievers' treatment, dispensation of $>1$ long-acting agonist with no other treatment, high frequency of drug treatment changes, $>15$ dispensations of controllers/year, high ratio of reliever to controller prescriptions and $>30$ tablets of beta-agonist/year) was created in order to define inadequate pharmaceutical treatment of childhood asthma. The clinics with a high percentage of children for whom the treatment provided was not in adherence with the clinical guidelines were located. The authors reported that $81 \%$ of the children were found to have at least 1 marker for inadequate treatment; $17.5 \%$ were found to have $>1$ marker [30].

Most guidelines recommend the provision of a written discharge plan with instructions for medications and follow-up until revision by the regular provider. The usefulness of such discharge plans was analyzed in several studies, most them showing clear improvement in health outcomes when combined with self-management education and regular medical review [3134].

The main limitation of our study resides in the way the information summarized in the questionnaires was obtained. When inquiring about disease history and previous medical management, access to care and the medical management of the $\mathrm{AE}$, we relied mainly on information obtained from patients' parents. However, the complete information on the medical management at PED and during hospitalization were extracted from the pediatric departments' files and was, therefore, reliable.

\section{Conclusion}

In conclusion, we found in the present study that suboptimal asthma prophylaxis, insufficient disease control and underuse of controller medication were associated with ethnic and socioeconomic disparities, although no differences were recorded in access to care and delivery of care, both at community clinics and ED as well. Non-adherence to asthma standard of care guidelines and lack of personalized action programs in community clinics, ED and at discharge emerged as major management concerns in both ethnic populations. The solution for asthma disparities seem to be related to a multidisciplinary approach involving nonmedical and medical professionals, tailored approaches with patients and families in order to identify needs and risk factors, more research and better use of care delivery and financial systems [35].

\section{References}

1. Weinick R, Zuvekas S, Cohen JW (2000) Racial and ethnic differences in access to and use of health services, 1977-1996. Med Care Res Rev 57: $36-54$

2. Akinbani LJ, Moorman JE, Simon AE, Schoendorf KC (2014) Trends in racial disparities for asthma outcome among children 0 to 17 years, 2001-2010. J Allergy Clin Immunol 134(3): 547-553.e5.

3. Agency for Healthcare Research and Quality (2006) National Healthcare Disparities Report. Rockville, MD: US Department of Health and Human Services, Agency for Healthcare Research and Quality; 2006: AHRQ Publication 07-0012.

4. Committee on Understanding and Eliminating Racial and Ethnic Disparities in Health Care (2003) Literature review. In: Smedley BD, et al. (Eds). Unequal Treatment: Confronting Racial and Ethnic Disparities in Health Care. Washington, DC: National Academics Press, pp. 285383.

5. McCaig LF, Burt CW (2003) National hospital ambulatory medical care survey: 2003 emergency department summary. Advance data 2005; pp. 358.

6. Ly N, McCaig LF (2002) National ambulatory medical care survey: 2000 outpatient department summary. Advance data 327:1-27.

7. Wood PR, Smith LA, Romero D, Bradshaw P, Wise PH, et al. (2002) Relationship between welfare status, health insurance status, and health and medical care among children with asthma. Am J Public Health 92(9): 1446-1452.

8. Franklin JM, Grunwell JR, Bruce AC, Smith RC, Fitzpatrick AM (2017) Predictors of emergency department use in children with persistent asthma in metropolitan Atlanta, Georgia. Ann Allergy Asthma Immunol 119(2): 129-136.

9. Boudreaux ED, Emond SD, Clark S, Camargo CA (2003) Race/ethnicity and asthma among children presenting to the emergency department: differences in disease severity and management. Pediatrics 111: e615-e621.

10. Akinbani L, Schoendorf K (2002) Trends in childhood asthma: prevalence, health care utilization, and mortality. Pediatrics 110 (pt 2): 315-322.

11. Schultz A, Northridge ME (2004) Social determinants of health: implications for environmental health promotion. Health Educ Behav 31(4): 455-471.

12. Lang DM, Polansky M (1994) Patterns of asthma mortality in Philadelphia from 1969 to 1991. N Engl J Med 331(23): 1542-1546.

13. Israel National Institute for Health Policy Research (2008) The quality parameters program in the community medicine in Israel. Public report for 2005-2007.

14. Fraser D, Givon-Lavi N, Bilenko N, Dagan R (2001) A decade (19891998) of pediatric invasive pneumococcal disease in 2 populations residing in 1 geographic location: implications for vaccine choice. Clin Infect Dis 33: 421-427.

15. The Israel Bureau of Statistics (2007).

16. Novack V, Avnon LS, Etzion O, Riesenberg K, Elbaz G, et al. (2007) Differences between Bedouin and Jewish populations in incidence and characteristics of patients hospitalized with community-acquired pneumonia. Ethn Dis 17(3): 441-446.

17. Shuval JT (1990) Health in Israel: patterns of equality and inequality. Soc Sci Med 31(3): 291-303.

18. Elhayany A, Parienty M (2008) Health care inequalities in Israel-the responsibility of the family physician. Harefuah (Hebrew) 147(12): 1004-1009. 
19. Pedersen SE, Hurd SS, Lemanske RF Jr, Becker A, Zar HJ, et al. (2010) Global strategy for the diagnosis and management of asthma in children 5 years and younger. Pediatr Pulmonol 46(1): 1-17.

20. Blanchard JC, Haywood YC, Scott C (2003) Racial and ethnic disparities in health: An emergency medicine perspective. Acad Emerg Med 10(11): 1289-1293.

21. Smedley BD, Stith AY, Nelson AR (2002) Institute of Medicine Committee on Understanding and Eliminating Racial and Ethnic Disparities in Health Care, Board on Health Sciences Policy. Unequal Treatment: Confronting Racial and Ethnic Disparities in Health Care, Washington, DC: National Academy Press, 2002.

22. Oster A, Bindman AB (2003) Emergency department visits for ambulatory care sensitive conditions; insights into preventable hospitalizations. Med Care 41(12): 198-207.

23. The Israeli Association of Allergy and Immunology, The Israeli Association of Pulmonology, The Israeli Association of Pediatric Pulmonology, The Israeli Society of Pediatric Immunology, The Israeli Society of Family Medicine, The Israeli Society of Pediatrics, The Israeli Society of Emergency Medicine. Guidelines, recommendations and position statements on asthma treatment. The Israel Medica Organization, The Scientific Council, Department of Quality Assurance, 2000.

24. National Institute for Clinical Excellence (2013) Quality Standard (QS25)-Asthma (including children and young people).

25. Paton J (2013) Asthma: standards of care. Arch Dis Child 98(12): 928929.

26. Chung KF, Wenzel SE, Brozeck JL, Bush A, Castro M, et al. (2014) International ERS/ATS guidelines on definition, evaluation and treatment of severe asthma. Eur Respir J 43(2): 343-373.
27. Cloutier MM, Jones GA, Hinckson V, Wakefield DB (2008) Effectiveness of an asthma management program in reducing disparities in care in urban children. Ann Allergy Asthma Immunol 100(6): 545-550.

28. Scribano PV, Lerer T, Kennedy D, Cloutier MM (2001) Provider adherence to a clinical practice guideline for acute asthma in a Pediatric Emergency Department. Acad Emerg Med 8(12): 1147-152.

29. Smith LA, Bokhour B, Hohman KH, Miroshnik I, Kleinman KP, et al. (2008) Modifiable risk factors for suboptimal control and controller medication underuse among children with asthma. Pediatrics 122(4): 760-769.

30. Peled R, Reuveni H, Pliskin JS, Benenson I, Hatna E, et al. (2006) Defining localities of inadequate treatment for childhood asthma; A GIS approach. Intern J Health Geographics 5: 3.

31. Lefevre F, Piper M, Weiss K, Mark D, Clark N, et al. (2002) Do written action plans improve patient outcomes in asthma? An evidence-based analysis. Fam Pract 51(10): 842-848.

32. Toelle BG, Ram FS (2004) Written individualized management plans for asthma in children and adults. Cochrane Database Syst Rev 2: CD002171.

33. Ducharme FM, Zemek RL, Chalut D, McGillivray D, Noya FJ, et al. (2011) Written action plan in pediatric emergency room improves asthma prescribing, adherence, and control. Am J Resp Crit Care Med 183(2): 195-203.

34. Mehring M, Donnachie E, Mutschler R, Hofmann F, Keller M, (2013) Disease management programs for patients with asthma in Germany: A longitudinal population-based study. Respir Care 58(7): 1170-1177.

35. Volerman A, Chin MH, Press VG. Solutions for asthma disparities. Pediatrics 139(7): 1-7.

\section{Your next submission with Juniper Publishers will reach you the below assets}

- Quality Editorial service

- Swift Peer Review

- Reprints availability

- E-prints Service

- Manuscript Podcast for convenient understanding

- Global attainment for your research

- Manuscript accessibility in different formats

( Pdf, E-pub, Full Text, Audio)

- Unceasing customer service

Track the below URL for one-step submission https://juniperpublishers.com/online-submission.php 